\title{
The Job Experience of Health Insurance Review Nurses in South Korea
}

\author{
Seong-Heui Kim \\ Assistant Professor, Department of Nursing, Daejin Univ., Hoguk-ro 1007, \\ Pocheon-si, Gyeonggi-do, 11159, Republic of Korea \\ nursingkim@daejin.ac.kr
}

\begin{abstract}
This study attempts to analyze the in-depth experiences of health insurance review nurses working at medical institutions in South Korea. The participants were 10 nurses working in the insurance review department of 3 senior general hospitals in Seoul and Gyeonggi-do. Data were collected through focus group interviews. As a result, the core category representing the job experiences of the health insurance review nurses was 'standing alone as nurse specialist without safeguards'. Four categories and 13 subcategories were derived around the core category. This study provides a comprehensive and holistic understanding of the job experience of health insurance review nurses working at medical institutions in Korean society. Therefore, this will provide new insights into the job of insurance review nurses and serve as the basis to complement the system for securing status. It will also contribute to strategies for job development based on their experiences.
\end{abstract}

Keywords: Health insurance, Review nurse, Job, Qualitative research

\section{Introduction}

The health insurance system of South Korea was expanded to cover the entire nation in 1989. The Korean government evaluates the adequacy of medical services through the Health Insurance Review and Assessment Service [1][2].

To cope with the control of the Health Insurance Review \& Assessment Service, medical institutions have their insurance review nurses who will be in charge of medical examination[3]. Recently, the Korean government has been pushing ahead with a policy to strengthen health insurance coverage under Catsplay "a country that is not concerned about hospital costs". As a result, the role of insurance audit nurses in medical institutions in charge of medical examination requests becomes more important [4].

On the other hand, insurance nurses in medical institutions experience many role conflicts and job stresses while performing a completely different type of job than the direct nursing practice performed by conventional clinical nurses [5].

Most health insurance review nurses have more than five years of clinical experience in the wards. And they are professionals with examination criteria, professional medical knowledge, and policy understanding regarding the adequacy of medical services. Nevertheless, they have not yet secured their position as a nurse specialist in the system [6].

Article history:

Received (May 16, 2019), Review Result (June 25, 2019), Accepted (August 11, 2019) 
In this regard, it is necessary to identify the actual activities and roles of medical institution insurance review nurses in Korea's rapidly changing medical system, to establish their job identity, and to seek developmental directions to be systematically recognized as professional nurses.

This study attempts to analyze the in-depth experiences of health insurance review nurses working at medical institutions in South Korea and to provide basic data for establishing policies and nursing strategies for them.

\section{Method}

\subsection{Research design}

This study is qualitative research using focus group interviews.

\subsection{Research subjects}

Participants in this study are 10 insurance review nurses currently working at three senior general hospitals in Seoul and Gyeonggi-do.

Participants were 3 in their 30s, 5 in their 40s, and 2 in their 50s with an average age of 46.5 years. Their clinical careers ranged from 8 to 14 years (average of 11.4 years) and insurance nurses from 7 to 22 years (average of 13.6 years).

For ethical reasons, the data collection began after the researcher informed the informants about the spontaneity of the research, the guarantee of the confidentiality of the research contents and utilization of the data for research purposes only, and then, accepted the agreement of the informants to participate in this research [7].

\subsection{Data collection}

The main data collection method in this study is a focus group interview. Data collection was conducted from June 2019 to August 2019. Focus group meetings were attended by four people in the first stage, three in the second, and three in the third each hospital. Each meeting took about two to three hours. The data collection was done up to the saturation point when new materials could no longer be found.

The main questions used in the interview were:

'How did you get started?'

'Can you tell me about your experience as an insurance nurse in a general hospital?'

'What do insurance nurses usually do?'

'How have you changed compared to when you first started working as an insurance nurse?'

'What do you think is the hardest part of doing this?'

'Could you tell me how it compares with the general ward nurse's work?'

\subsection{Data analysis}

Strauss \& Corbin's continuous comparative analysis was applied to examine the structure of the job experience of insurance nurses [8][9][10].

Data analysis was simultaneously performed as the data were being collected.

During the study, the researcher read the collected data repeatedly and performed open coding to conceptualize and categorize them into similar sentences and units. 
Axial coding was carried out to specifically link the relationships between categories and subcategories found through open coding.

Finally, the core categories were derived by integrating all analyses. Finally, the results of the analysis were shown to three participants to confirm their meanings.

\section{Results}

As a result, the core category representing the job experiences of the health insurance review nurses was 'standing alone in a fenceless position'

Four categories and 13 subcategories were derived from the core category

4 Categories are 'Enjoying the benefits of long-awaited regular work', 'Suffering from Pressure to increase hospital income', 'Skepticism and conflict about work', and 'Enduring in a position without guarantee'.

The relationship between the core categories, categories, and subcategories is shown below.

\subsection{Enjoying the benefits of long-awaited regular work}

The category "Enjoying the benefits of long-awaited regular work" has three subcategories: 'Privilege to escaping from shift work', 'Enjoying ordinary everyday life I have longed for', and 'Pride in the professionalism of the work environment'.

\subsubsection{Privilege of escaping from shift work}

All the participants looked forward to regular work due to the difficulties of shift work. They were informed that the insurance nurse's work was difficult, but they could never refuse even the condition that prevented them from working at night. They thought that being an insurance audit nurse was a more specialized task, doing work differently from general nurses.

\subsubsection{Enjoying ordinary everyday life I have longed for}

Subjects said that when they became insurance nurses, they were thankful that they could live normal life like other ordinary workers. In other words, insurance nurses were grateful and fascinated by the fact that they were able to enjoy a normal life that they could not enjoy due to their shift work and were happy to be able to move together with the same timetable as their families.

\subsubsection{Pride in the professionalism of the work environment}

Participants became proud and motivated to work more professionally through the work environment at the beginning of their work. This is because they have their own space with their desks and computers, and have the flexibility to adjust their work according to their schedule, not the doctor's order, or judgment based on screening standards or laws. It also raises expectations for self-development and development.

\subsection{Suffering from Pressure to increase hospital income}

The category "Suffering from Pressure to increase hospital income" has three subcategories: 'Life is driven by the deadline', 'Stress due to cuts in Billing of medical expenses, and 'Responding quickly to turbulent medical policies'. 


\subsubsection{Life is driven by the deadline}

Participants reported that they were under great stress like new nurses because of the unfamiliar task that was too far from the clinical nurse's job after moving to the department. In particular, the greatest pressure was on them to finish work on a set date. Participants frequently worked overtime or holiday work to meet deadlines.

\subsubsection{Stress due to cuts in Billing of medical expenses}

Participants appealed that their ability was assessed by the reduction of medical bills they claimed. Indeed, the rate of cut was determined by whom the patients who used the high cost of medical care were allocated, rather than the nurses' ability to screen. Nevertheless, the blame was placed on them.

\subsubsection{Responding quickly to turbulent medical policies}

Participants were struggling with ever-changing healthcare systems and policies, criteria for examination according to the social climate, and intricate standards. This was because they had to be held accountable if they missed the application of the criteria or made wrong pay decisions.

\subsection{Skepticism and conflict about work}

The category "Skepticism and conflict about work" has four subcategories: "human relationships that are being damaged', 'Working environment that is getting worse ', 'Conflict of identity between hospital and patient', 'Burnout due to multiple tasks requiring super powers'.

\subsubsection{Human relationships that are being damaged}

Participants experienced conflicts in their relationships with people in various fields after becoming insurance examiners. In particular, they experienced many pains and fears due to urges and protests from ward nurses and doctors, the transfer of responsibility of administrative staff, the authoritative attitudes of nurses in the assessment agency, and complaints from patients or guardians.

\subsubsection{Working environment that is getting worse}

Participants said that the burden of work has been increasing due to the recent policy of strengthening national security. In addition, to solve this problem, they had to work overtime and endless hours, and recently, they had to work on Saturdays and Sundays. Participants said that the benefits of regular work, which had previously been the only privilege of an insurance nurse, were almost lost.

\subsubsection{Conflict of identity between hospital and patient}

Participants said they were in conflict and confusion between the patient and the hospital. In practice, insurance nurses are likely to play a role in increasing hospital revenue, limiting the treatment of patients, and contradicting their interests.

\subsubsection{Burnout due to multiple tasks requiring superpowers}


Participants said that there are too many more roles to be given to insurance nurses. They also said that if they were left to work without notice, they had to learn and do it.

\subsection{Enduring in a position without a guarantee}

The category "Enduring in a position without guarantee" has three subcategories: 'A sense of alienation due to the ambiguity of my organization', 'Status threatened by the discontinuance of clinical nurse career ', 'Longing to be an institutional guarantee of professionalism'.

\subsubsection{A sense of alienation due to the ambiguity of my organization}

Since insurance nurses first joined the nursing organization, they were unable to have a sense of belonging or fellowship as administrative staff and were placed in the position of strangers. This led them to realize that they should be left alone while experiencing a sense of alienation.

\subsubsection{Status threatened by the discontinuance of clinical nurse career}

Participants experienced a threat or anxiety due to the discontinuance of clinical nurse careers as their careers increased. Indeed, it is not easy to return to a general nurse because the insurance business is too far from that of a general nurse, and medical systems and devices have changed rapidly in recent years.

\subsubsection{Longing to be an institutional guarantee of professionalism}

Participants recognized that the establishment of an institution that recognizes insurance nurses as specialist nurses was urgent to secure a stable position and longed for legislation as soon as possible.

\section{Conclusion and Discussion}

Through this study, it was confirmed that insurance nurses are experiencing heavy work and psychological stress while playing various roles for the hospital's profits in exchange for the small benefit of escape from shift work. In addition, they had to endure the threat of alienation and career interruption from the organization without institutional guarantees for the profession. Therefore, it is necessary to establish a system that guarantees their status at the national level so that insurance nurses can fulfill their roles with satisfaction and pride in their work.

This study has the following significance. First, this study is meaningful in that it provides the foundation for constructing a grounded theory for the job experience of insurance review nurses working in medical institutions for the first time in Korean society where the whole nation receives health insurance benefits.

Second, it is significant that they have vividly described how they are working in terms of their view as an insurance nurse.

Third, this study is meaningful in that it provides the foundation for constructing a grounded theory for the job experience of insurance review nurses working in medical institutions for the first time in Korean society where the whole nation receives health insurance benefits. 
This study shows that insurance audit nurses are experiencing confusion of identity due to various role burdens and tasks rather than satisfaction while performing their duties.

To reduce the conflict and burden on these jobs, it was urgent to establish an institutional status for the insurance nurse.

The results of this study will provide a foundation for supplementing the system for securing the status of insurance review nurses and supporting the job development program for insurance nurses in line with the social situation in Korea.

\section{References}

[1] H. Y. Hwang, "The development job standards for advanced health insurance review nurses," The Journal of Korean Nursing Administration Academic Society, vol.15, no.2, pp.264-274, (2009)

[2] J. R. Kim, S. R. Suh, and J.W. Shin, "Work stress and fatigue among medical insurance review nurses," Korean Journal of Health Education and Promotion, vol.26, no.4, pp.63-70, (2009)

[3] S. H. Choi, E. J. Lee, and M. J. Park, "Relationship between work stress and job satisfaction experienced by nurses in medical insurance," The Korean journal of fundamentals of nursing, vol.10, no.3, pp.354-360, (2003)

[4] I. O. Kim, M. S. Koh, and S. H. Hwang, "A study on the prediction of the projected workforce of certified insurance reviewer nurses (CIRNs) in Korea," The Journal of Korean Nursing Administration Academic Society, vol.9, no.2, pp.243-250, (2003)

[5] J. L. Park, S. H. Jung, and Y. M. Chae, "Analysis of influencing factors that influence the job satisfaction of nurses involved in medical insurance reviews," Health Policy and Management, vol.17, no.4, pp.82-98, (2007) DOI: 10.4332/KJHPA.2007.17.4.082

[6] S. I. Jung, E. N. Lee, and Y. S. Song, "The main \& buffering effects of perceived social support on burnout of insurance review nurses," The Journal of Korean Nursing Administration Academic Society, vol.12, no.3, pp.482-490, (2006)

[7] G. B. Kim, "Focus group method, in qualitative research methodology," Edited H.Y. Ryu, Hyun Moon Sa, Seoul, pp. 381-392, (2005)

[8] Corbin. J and Strauss A., "Basics of qualitative research: techniques and procedures for developing grounded theory (3rd ed.)," CA: Sage, Thousand Oaks, (2008)

[9] Morse. J. M, "Disseminating qualitative research," In Disseminating primary care research, CA: Sage, Thousand Oaks, pp. 59-7

[10] Park M., Yeom H., and Yong S.J., "Hospice care education needs of nursing home staff in South Korea: a cross-sectional study," BMC Palliat Care, vol.18, article no.20, (2019) doi:10.1186/s12904-019-0405-X 